\title{
Insomnia, Short Sleep, And Snoring In Mid-To-Late Pregnancy: Disparities Related To Poverty, Race, And Obesity
}

\author{
David A Kalmbach (D) \\ Philip Cheng (D) \\ Roopina Sangha $\mathbb{D D}^{2}$ \\ Louise M O'Brien ${ }^{3}$ \\ Leslie M Swanson ${ }^{4}$ \\ Laura Palagini ${ }^{5}$ \\ Luisa F Bazan ${ }^{6}$ \\ Thomas Roth (D) \\ Christopher L Drake $\mathbb{D}^{\prime}$ \\ 'Thomas Roth Sleep Disorders and \\ Research Center, Henry Ford Health \\ System, Novi, MI, USA; ${ }^{2}$ Department of \\ Obstetrics and Gynecology, Henry Ford \\ Health System, Detroit, MI, USA; \\ ${ }^{3}$ Departments of Obstetrics \\ \&Gynecology and Neurology, University \\ of Michigan, Ann Arbor, MI, USA; \\ ${ }^{4}$ Department of Psychiatry, University of \\ Michigan Medical School, Ann Arbor, MI \\ USA; ${ }^{5}$ Departments of Neuroscience and \\ Psychiatry, University of Pisa, Pisa, Italy; \\ ${ }^{6}$ Division of Sleep Medicine, Henry Ford \\ Health System, Detroit, MI, USA
}

Correspondence: David A Kalmbach

Thomas Roth Sleep Disorders \& Research Center, Henry Ford Health System, Novi, MI, USA

Tel + I2483253938

Emaildkalmbal@hfhs.org
This article was published in the following Dove Press journal: Nature and Science of Sleep

Objective: To characterize sleep habits and parameters among women in mid-to-late pregnancy and to identify disparities associated with poverty, race, and obesity.

Design: Cross-sectional.

Setting: Large multi-site health system in Metro Detroit.

Participants: A total of 267 pregnant women (27.3\% non-Hispanic black; gestational age: $27.99 \pm 1.20$ weeks) completed online surveys on sleep quality, insomnia symptoms, sleep aid use, signs/symptoms of sleep-disordered breathing, and sociodemographics. Body mass index (BMI) and patient insurance were derived from medical records.

Results: As high as $76.2 \%$ of the women reported global sleep disturbance, $30.6 \%$ endorsed snoring, $24.3 \%$ sleep $<6 \mathrm{hrs} / \mathrm{night}$, and over half screened positive for clinical insomnia. Yet, only $3.4 \%$ of the women reported an insomnia diagnosis and $3.0 \%$ reported a sleep apnea diagnosis. In unadjusted models, poverty, Medicaid coverage, self-identifying as black, and obesity before and during pregnancy $(\mathrm{BMI} \geq 35)$ were associated with a wide range of sleep problems. However, adjusted models revealed specificity. Poverty was uniquely related to increased insomnia symptoms and trouble sleeping due to bad dreams. Obesity before pregnancy was related to poor sleep quality, snoring, sleep aids, and short sleep. Black women reported shorter sleep duration than white women but differed on no other sleep parameters.

Conclusion: Clinical signs of insomnia and sleep-disordered breathing are common in midto-late pregnancy, but most cases go undetected. Problematic sleep disproportionately affects women in poverty, who self-identify as black, and who are obese before pregnancy. Povertyrelated sleep issues are linked to insomnia, obesity-related disparities center on sleep-related breathing and medication use, and racial disparities relate to short sleep.

Keywords: sleep aids, sleep apnea, Medicaid, perinatal, prenatal

\section{Introduction}

Poor quality and insufficient sleep are endemic to pregnant women. ${ }^{1-7}$ Insomnia and sleep-disordered breathing (SDB) are among the two most common sleep issues in the prenatal period. Estimates indicate that insomnia may affect $>50 \%$ of the pregnant women and that severity is highest in the $3 \mathrm{rd}$ trimester. ${ }^{5}$ SDB shows similar patterns based on polysomnography (PSG) and home sleep testing (HST) and estimated prevalence of obstructive sleep apnea (OSA) in the US is between $3.6 \%$ and $10.5 \%$ in the 1 st and 2 nd trimesters, which increases to $26.7 \%$ in the 3 rd trimester. ${ }^{8,9}$ Even absent of a formal OSA diagnosis, $30-40 \%$ of the pregnant women endorse snoring, 
a prognostic marker for OSA.,2,6,7 Like prenatal trends in global sleep disturbance ${ }^{3}$ and insomnia, ${ }^{5,10}$ SDB symptoms and OSA frequencies increase as pregnancy progresses. ${ }^{1-3,8}$

Prenatal sleep problems warrant serious attention by health-care professionals given that many perinatal complications are associated with insomnia and short sleep (e.g., more Caesarean sections, preterm birth, low birth weight, maternal depression, suicidality) ${ }^{11-19}$ and with SDB (e.g., pre-eclampsia, hypertension, diabetes, maternal depression). ${ }^{4,6,7,20-22}$ Despite some mixed findings in the literature regarding trajectories of sleep symptoms across pregnancy, compelling evidence including prospective data suggest that sleep problems are most prevalent and severe in late pregnancy. ${ }^{3,5,10,11,23}$ This tendency is important as it suggests that early detection of sleep difficulties during routine prenatal care with an obstetrician or midwife may provide opportunity for prevention or early intervention, potentially before a sleep disorder becomes fully established or is exacerbated as pregnancy progresses. Early intervention to improve sleep and prevent its deterioration may potentially reduce the risk of the perinatal complications associated with poor maternal sleep.

Identifying groups vulnerable to sleep pathology during pregnancy is critical to maximize the ability to detect at-risk cases early. In the broader adult clinical sleep literature, marginalized populations have been shown to be especially prone to sleep problems and disorders. In the US, sleep morbidity is elevated among individuals of low income and financial strain, ${ }^{24-27}$ racial minorities, ${ }^{27-31}$ and the obese. ${ }^{32}$ Sleep disparities in relation to these factors have been explored comparatively less in pregnant women, although some emerging evidence reveals similar trends such that sleep quality is poor among those with low income, ${ }^{1}$ and that OSA and self-reported SDB symptoms are elevated for pregnant women who identify as black and are obese. ${ }^{7,8,21,33}$

Yet, the extant literature on prenatal sleep disparities is limited in two key ways: First, sleep disparities is a severely understudied and underappreciated area of research in pregnant women. Income/race/obesity-related disparities have not been the primary focus of prenatal sleep research. Rather, identified disparities have been characterized in prenatal sleep studies as a form of context for primary investigations (e.g., in a prior study on the relationship between snoring and depression during pregnancy, we observed that snorers were more likely to have been obese before pregnancy ${ }^{21}$ ). As a result, current knowledge on sleep disparities in pregnancy remains rather superficial and comprehensive investigations on the topic are non-existent. Second, low socioeconomic status (SES), racial minority status, and obesity are associated with one another, ${ }^{34-36}$ but studies examining sleep inequalities related to socioeconomic position, race, or obesity do not routinely control for potential effects of the other factors; this is particularly true in the relatively small body of literature on prenatal sleep. Thus, a critical need exists to characterize common prenatal sleep symptoms and to identify disparities in these parameters related to income, race, and obesity.

As the first comprehensive study of sleep disparities related to poverty, race, and obesity in pregnant women, we took a descriptive and exploratory approach to our data. First, we sought to first characterize the sleep habits of pregnant women in mid-to-late pregnancy, when prenatal sleep is at its worst, and to explore disparities related to poverty, race, and obesity. We examined overall reports of sleep disturbance, insomnia symptoms, short sleep $(<6$ hrs/night), sleep aid use, and clinical signs of SDB. Notably, we administered commonly used and standardized sleep measures and reported rates based on all available clinical cutoffs to maximize comprehensiveness of our sleep characterization. We explored sleep disparities in relation to poverty status (based on annual household income and Medicaid insurance coverage), racial minority status, and obesity. Second, we conducted multivariate regression models estimating sleep symptoms as predicted by poverty, race, and obesity, which addressed issues regarding potential confounding associations among these sociodemographic factors while identifying independent associations with key sleep symptoms. Broadly, we predicted that sleep problems would be high during pregnancy and that women in poverty, of minority racial background, and who were obese before and during pregnancy would endorse elevated rates of sleep problems.

\section{Participants And Methods}

\section{Participants And Procedures}

The present study was conducted in a 6-hospital health system in Southeastern Michigan. All procedures were approved by the institutional review board. The study was part of a randomized controlled trial (RCT) comparing digital/internet-based cognitive-behavioral therapy for insomnia vs sleep hygiene education on perinatal insomnia. Data collected in this phase of the study were used to screen for eligibility into the RCT. Pregnant women receiving prenatal care in the health system's obstetrics 
clinics were invited to complete this portion of the study. Due to our focus on mid-to-late pregnancy, only women in the late second trimester and early third trimester were contacted (i.e., all patients between gestational weeks 25 and 30 with listed email contact information in their electronic medical records). Invitations advertising a study on perinatal sleep (without mentioning either that we were focused on poor sleep or that we were evaluating sleep treatments) were sent via email and phone calls to 3585 pregnant obstetric patients. A total of 535 women contacted us with interest in our study. After discussing study details over the phone, 272 women consented to completing the online surveys, which were hosted by Qualtrics. Of the surveys sent, 267 women provided sufficient data for analysis (i.e., reported demographic information and completed at least two primary outcome measures of interest). These data were collected between September 12, 2018 through March 9, 2019.

\section{Measures}

\section{Sleep Measures}

Sleep disorder history was assessed by asking all subjects whether they "had ever been diagnosed with insomnia, sleep apnea, or any other sleep disorder?" Those who affirmed were then prompted to specify which diagnosis/ es they had received. Insomnia symptoms were measured using the Insomnia Severity Index (ISI). ${ }^{37}$ Total scores on the ISI represent overall insomnia symptom levels over the prior 2 weeks with higher scores indicating greater severity. The original cutoffs include ISI $=8-14$ for subthreshold insomnia and ISI $\geq 15$ for clinical insomnia. Psychometric re-evaluation of the ISI offered ISI $\geq 10$ as the ideal cut-point for identifying insomnia cases in community samples, and ISI $\geq 11$ as the ideal cut-point for identifying cases in clinical samples. ${ }^{38}$ Global sleep quality/sleep disturbance was measured using the Pittsburgh Sleep Quality Index ${ }^{39}$ (PSQI). The PSQI measures a wide range of sleep parameters over the past month including sleep duration, sleep latency, sleep aid use, and sleep difficulties related to insomnia, breathing difficulties, environmental stimuli, and other factors over the prior month. A global cutoff score of PSQI $>5$ is the original cutoff for differentiating good vs poor sleepers, which has been widely supported. However, a cut-point of PSQI $>8$ has been recommended for identifying especially poor sleepers within populations marred by elevated sleep disturbance, including patients with cancer ${ }^{40}$ or traumatic brain injury. ${ }^{41,42}$ In addition to measuring overall sleep quality, we used the PSQI to classify patients as having short sleep (item $4 \mathrm{a}:<6 \mathrm{hr} /$ night), sleep onset insomnia symptoms (item 5a: endorsing inability to fall asleep within 30 mins on $\geq 3$ nights/week) and sleep maintenance insomnia symptoms (item 5b: endorsing difficulties with nighttime awakening and/or early morning awakenings on $\geq 3$ nights/week). This method of classifying sleep onset insomnia symptoms with the PSQI has been supported by prior research, ${ }^{4-43}$ and this short sleep cutoff is consistent with current practices for both objective and self-reported sleep duration. ${ }^{28,44}$ In addition to these measures, subjects were assessed for symptoms of SDB including snoring ("Do you snore?" Yes/No), whether they have stopped breathing during sleep (Yes/No), and whether they have woken up gasping for air (Yes/No).

Sociodemographic characteristics, medical information, and pregnancy-related factors were reported by subjects via an online survey, except for patient insurance provider and body mass index (BMI) prior to pregnancy (within 1 year of study participation) and during pregnancy at time of assessment, which were collected from electronic medical records (EMRs). Notably, pre-pregnancy BMI could not be collected for 41 out of 267 women in our study, because (1) some patients did not have an appointment with a measured weight within a year of participating or (2) some patients were not in our healthcare system until they became pregnant. These women did not differ from the other 226 women in our study on key variables. In the present study, our central focus was to identify disparities in sleep based on poverty, race, and obesity. Thus, poverty was operationalized as a household income $<\$ 20,000$, which is consistent with the US poverty line of $\$ 21,330$ for a household of 3 per the US Department of Health and Human Services 2019 Poverty Guidelines and with the operationalization used in a recent large-scale epidemiological study on disparities in sleep symptoms. ${ }^{45}$ In addition, we examined Medicaid insurance as a proxy indicator of poverty status. Insurance was derived from EMRs and coded as a binary variable (Medicaid or Other insurance) and group comparisons are reported in Supplementary Table 1. For our racial comparisons of sleep parameters, we compared only women who self-identified as non-Hispanic white or non-Hispanic black as these were the only two groups with sufficient representation for analysis (we followed these analyses with white vs minority comparisons, the latter group including all non-white individuals. The results are presented in Supplementary Table 2, but we caution against over-interpreting these results due to the substantial racial heterogeneity inherent to a broad "minority 
group"). For our obesity-related comparisons, we used a cutoff of BMI $\geq 35$ both prior to and during pregnancy. We specifically chose this cutoff as it represents class II-III obesity, reflects criteria from the widely used STOP-BANG sleep apnea screener, ${ }^{46}$ and is consistent with data showing that pre-pregnancy BMI $\geq 35$ is a better predictor of latepregnancy OSA than $\mathrm{BMI} \geq 25$ or $\geq 30$.

\section{Analyses}

All analyses were conducted in SPSS version 25 (IBM, Armonk, NY). Results were interpreted as significant when $p<0.05$. We first explored descriptives for the full sample including sociodemographics, pregnancy-related information, and sleep parameters. Next, we took a twostep approach to exploring sleep disparities. In step 1, we compared sleep symptoms between groups based on poverty, race (non-Hispanic white vs non-Hispanic black [the only two racial groups with sufficient representation for comparison]), and obesity (BMI was $\geq 35$ vs $\mathrm{BMI}<35$; separately for pre-pregnancy BMI and during pregnancy BMI at time of assessment). For continuous outcomes, we used independent samples $t$-tests to test for significance and presented effect sizes using Cohen's d. For binary outcomes, we used chi-square analysis and presented effect sizes using rate ratios (RR).

In step 2, we estimated clinical sleep outcomes while controlling for potential confounding associations among poverty, race, and obesity. Specifically, we conducted multiple regression models (linear for continuous outcomes, logistic for binary outcomes) estimating sleep parameters as predicted by poverty status, race (white or black), and obesity to identify which of these factors was/were independently related to sleep problems. Importantly, this two-step process allows us to characterize changes in associations between bivariate models (consistent with extant literature on sleep disparities in the perinatal period) and multivariate models.

\section{Results}

\section{Sample Characteristics And Sociodemographics}

Full sample characteristics are reported in Table 1. The average age for women in our sample was 29.76 years $( \pm 4.72)$ and average gestational age was 27.99 weeks $( \pm 1.20$, range $25-37)$. Most women planned their pregnancy (65.5\%), 22.8\% reported a history of miscarriage, and $64.0 \%$ were multiparous. Reported rates of diabetes and hypertension (pre-pregnancy or gestational) and pre-eclampsia were low (all $<5 \%$ ). An estimated $17.2 \%$ of the sample reported living in poverty. Slightly over half of the sample identified as non-Hispanic white and a little more than a quarter identified as nonHispanic black. All other racial categories each represented $<5 \%$ of the sample. Prior to pregnancy, mean BMI scores were in the overweight category and $13.3 \%$ of the sample had BMI scores $\geq 35$. In mid-to-late pregnancy, mean BMI was in the class I obesity range and $21.8 \%$ of the sample had BMI scores $\geq 35$. Only 18 out of 267 (6.7\%) reported having been diagnosed with any sleep disorder in their lifetimes.

\section{Overall Sleep Habits And Parameters Sleep Parameters And Disturbance}

The average nightly reported sleep duration was 6 hrs and 37 mins and $24.3 \%$ of the sample reported averaging $<6 \mathrm{hrs}$ of sleep per night. Nearly half of the sample reported napping during the day $(n=128 / 267 ; 47.9 \%)$. Few women $(n=9$; $3.4 \%$ ) reported having been diagnosed with insomnia. Per the PSQI, $76.2 \%$ of the women screened positive for significant sleep disturbance (i.e., PSQI > 5; see Table 2 for full results). And when using the more conservative cutoff of PSQI $>8$, typically reserved for populations of especially poor sleepers, $44.2 \%$ of the women screened positive for significant sleep disturbance. Similarly, $58.4 \%$ of the women in our study screened positive for clinical insomnia based on the revised ISI cutoff for epidemiological research (ISI $\geq 10) .{ }^{38}$ Importantly, all 9 women with insomnia diagnoses were correctly classified using the ISI $\geq 10$ cut-point. However, that meant that $147 / 156$ women who screened positive for insomnia (94.2\%) did not report an insomnia diagnosis. A total of 34 women (12.7\%) reported having used sleep aids in the prior month.

We then examined factors associated with trouble sleeping $\geq 3$ days per week on the PSQI (Table 2). Waking to use the bathroom (81.3\%) and frequent nighttime or early morning awakening (i.e., sleep maintenance insomnia symptoms; $69.7 \%$ ) were the two most highly endorsed factors associated with persistent sleep difficulties. Inability to fall asleep within 30 mins on $\geq 3$ days/week (i.e., sleep onset insomnia symptoms) was endorsed by $31.5 \%$ of the sample, which is consistent with the sample's mean sleep latency of 32.61 mins.

\section{Sleep-Related Breathing Difficulties}

Only 8 women had been diagnosed with OSA (3.0\%) and 1 woman reported a diagnosis of upper airway resistance syndrome (UARS: $0.4 \%$; Table 2). By comparison, 30.6\% of the women reported that they snore, $4.9 \%$ reported that they stop breathing during sleep, and $9.1 \%$ reported having 
Table I Sample Demographics And Pregnancy Characteristics (n=267)

\begin{tabular}{|c|c|c|c|}
\hline & M $\pm S D$, Range & & n, \% \\
\hline Age & $29.76 \pm 4.72,20-44$ & Employment & \\
\hline Gestational week & $27.99 \pm 1.20,25-37$ & Full-time & $103 / 267 ; 52.1 \%$ \\
\hline BMI, pre-pregnancy & $27.59 \pm 7.20,17.17-70.64$ & Part-time & $49 / 267 ; 18.4 \%$ \\
\hline BMI, at assessment & $30.65 \pm 7.16,19.13-70.67$ & Student & $22 / 267 ; 8.2 \%$ \\
\hline Exercise & $3.06 \pm 1.90$ days/week & $\begin{array}{l}\text { Relationship } \\
\text { Single }\end{array}$ & $25 / 267 ; 9.4 \%$ \\
\hline Prior Sleep Disorder Diagnosis & $\mathrm{n}, \%$ & In relationship, unmarried & $5 \mathrm{I} / 267 ; 19.1 \%$ \\
\hline No diagnosis & $249 / 267 ; 93.3 \%$ & Married & I89/267; 70.8\% \\
\hline Insomnia & $9 / 267 ; 3.4 \%$ & Separated or Divorced & $2 / 267 ; 0.7 \%$ \\
\hline Sleep apnea & $8 / 267 ; 3.0 \%$ & Highest education & \\
\hline \multirow[t]{3}{*}{ UARS } & $\mathrm{I} / 267 ; 0.4 \%$ & No HS diploma or GED & $3 / 267 ; 1.1 \%$ \\
\hline & & Highschool or GED & $87 / 267 ; 32.6 \%$ \\
\hline & & Trade, technical, vocational & $15 / 267 ; 5.6 \%$ \\
\hline Planned pregnancy & $175 / 267 ; 65.5 \%$ & Associate degree & $30 / 267 ; 11.2 \%$ \\
\hline History of miscarriage & $61 / 267 ; 22.8 \%$ & Bachelor's degree & $70 / 267 ; 26.2 \%$ \\
\hline Prior parturition & $17 \mid / 267 ; 64.0 \%$ & Graduate or Professional Degree & $52 / 267 ; 19.5 \%$ \\
\hline Diabetes & & Doctorate & $10 / 267 ; 3.7 \%$ \\
\hline Pre-pregnancy & $0 / 267 ; 0.0 \%$ & Racial identity & \\
\hline Gestational & $12 / 267 ; 4.5 \%$ & White & $149 / 267 ; 55.8 \%$ \\
\hline Pre-eclampsia & & Black & $73 / 267 ; 27.3 \%$ \\
\hline Clinical signs, no diagnosis & $9 / 267 ; 3.4 \%$ & Asian & II/267; 4.1\% \\
\hline Diagnosed & $5 / 267 ; 1.9 \%$ & Middle Eastern & $12 / 267 ; 4.5 \%$ \\
\hline Hypertension & & Hispanic or Latinx & $10 / 267 ; 3.7 \%$ \\
\hline Pre-pregnancy & $5 / 267 ; 1.9 \%$ & Multiracial & II/267; 4.1\% \\
\hline Gestational & $2 / 267 ; 0.7 \%$ & Other & $1 / 267 ; 0.4 \%$ \\
\hline Poverty ( $<\$ 20 \mathrm{~K}$ annual income) & $45 / 26 I ; 17.2 \%$ & & \\
\hline Medicaid insurance & $78 / 267 ; 29.2 \%$ & & \\
\hline
\end{tabular}

Abbreviations: BMI, body mass index $\left(\mathrm{kg} / \mathrm{m}^{2}\right)$, derived from electronic medical records; UARS, upper airway resistance syndrome; HS, High school; GED, General Education Development degree.

woken up gasping for air. Only 6 of the 81 snorers $(7.4 \%)$ were diagnosed with OSA and none were diagnosed with UARS. Just 5 out of 13 women who reported that they stop breathing during sleep had been diagnosed with sleep apnea and none were diagnosed with UARS. Of the 24 women who reported waking up gasping for air, just 3 $(12.5 \%)$ had been diagnosed with OSA and none with UARS.

\section{Poverty-Related Disparities In Prenatal Sleep}

We next explored demographic and sleep differences based on poverty status per annual household income and Medicaid status. As expected, most patients below the poverty line were covered by Medicaid insurance (Table 2). And although patterns of sleep disparities were somewhat similar for the two indicators of socioeconomic position, sleep inequalities were more pronounced when comparing groups based on income rather than based on Medicaid insurance. Thus, we primarily focus on income-based poverty status here (see Table 2 for full results), whereas Medicaid-related results can be found in Supplementary Table 1. Regarding incomebased poverty, black women were nearly three times more likely to live in poverty than white women $(R R=2.82$; Table 2). BMI prior to and during pregnancy did not differ between income classes.

Pregnant women in poverty reported moderately greater insomnia symptoms and were more likely to screen positive for clinical insomnia on the ISI than women not in poverty (Cohen's $d=0.59$; full results in Table 2). Similarly, PSQI scores were moderately higher 
Table 2 Comparing Sleep Parameters Between Pregnant Women Above And Below The Poverty Line

\begin{tabular}{|c|c|c|c|c|}
\hline & All Women $n=267$ & $\begin{array}{l}\text { Poverty } \\
n=45 / 26 I\end{array}$ & $\begin{array}{l}\text { Non-Poverty } \\
n=216 / 261\end{array}$ & \\
\hline Medicaid insurance & $78 / 267 ; 29.2 \%$ & $40 / 45 ; 88.9 \%$ & $36 / 216 ; 16.7 \%$ & $\chi^{2}=94.1 \mathrm{I} * * *, \mathrm{RR}=5.32$ \\
\hline Black \% & $73 / 261 ; 27.9 \%$ & $27 / 40 ; 67.5 \%$ & $42 / 176 ; 23.9 \%$ & $\chi^{2}=28.55 * * *, \mathrm{RR}=2.82$ \\
\hline $\begin{array}{l}\text { BMI, pre-pregnancy } \\
\text { M } \pm \text { SD } \\
\text { n; } \% \geq 35 \\
\text { BMI, at assessment } \\
\text { M } \pm \text { SD } \\
\text { n; } \% \geq 35\end{array}$ & $\begin{array}{l}27.59 \pm 7.20 \\
30 / 226 ; 13.3 \\
30.65 \pm 7.16 \\
56 / 257 ; 21.8\end{array}$ & $\begin{array}{l}28.39 \pm 7.57 \\
8 / 35 ; 22.9 \% \\
31.36 \pm 30.39 \\
12 / 41 ; 29.3 \%\end{array}$ & $\begin{array}{l}27.36 \pm 7.15 \\
21 / 185 ; 11.4 \% \\
30.39 \pm 7.03 \\
41 / 210 ; 19.5 \%\end{array}$ & $\begin{array}{l}t(2 \mid 8)=0.76, p=0.44 \\
\chi^{2}=3.41, p=0.07 \\
t(249)=0.79, p=0.43 \\
\chi^{2}=1.96, p=0.38\end{array}$ \\
\hline 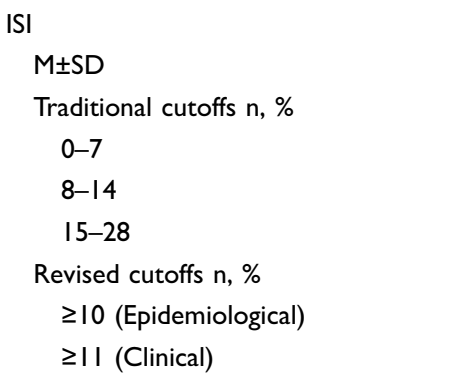 & 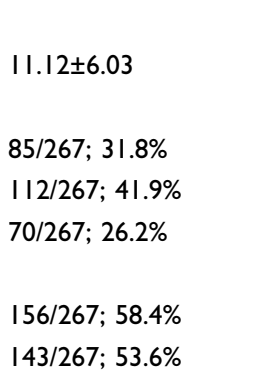 & $\begin{array}{l}14.04 \pm 6.16 \\
8 / 45 ; 17.8 \% \\
16 / 45 ; 35.6 \% \\
21 / 45 ; 46.7 \% \\
\\
33 / 45 ; 73.3 \% \\
32 / 45 ; 71.1 \%\end{array}$ & $\begin{array}{l}10.52 \pm 5.83 \\
76 / 216 ; 35.2 \% \\
92 / 216 ; 42.6 \% \\
48 / 216 ; 22.2 \% \\
119 / 216 ; 55.1 \% \\
107 / 216 ; 49.5 \%\end{array}$ & $\begin{array}{l}\mathrm{t}(259)=3.65^{* * *}, \mathrm{~d}=0.59 \\
\mathrm{ISI} \geq 8: \chi^{2}=5.17^{*}, \mathrm{RR}=1.27 \\
|\mathrm{~S}| \geq 15: \chi^{2}=I I .44^{* *}, \mathrm{RR}=2.10 \\
\chi^{2}=5.10^{*}, \mathrm{RR}=\mathrm{I} .33 \\
\chi^{2}=6.96^{* *}, \mathrm{RR}=1.44\end{array}$ \\
\hline $\begin{array}{l}\text { PSQI } \\
\text { Total score M } \pm \text { SD } \\
>5 \text { (Traditional samples) } \\
>8 \text { (Clinical samples) } \\
\text { Sleep latency in minutes } \\
\text { Sleep duration } \\
\text { Hours per night } \\
\%<6 \text { hrs/night } \\
\text { Trouble sleep } \geq 3 \text { days/week due to: } \\
\text { Cannot fall asleep within } 30 \text { mins } \\
\text { Nighttime or early morning waking } \\
\text { Needing to use the bathroom } \\
\text { Cannot breathe comfortably } \\
\text { Cough or snore loudly } \\
\text { Bad dreams } \\
\text { Pain } \\
\text { Sleep aid use within past month }\end{array}$ & $\begin{array}{l}6.61 \pm 1.35 \\
65 / 267 ; 24.3 \% \\
84 / 267 ; 31.5 \% \% \\
186 / 267 ; 69.7 \% \\
217 / 267 ; 81.3 \% \\
44 / 267 ; 16.5 \% \\
22 / 267 ; 8.2 \% \\
40 / 267 ; 15.0 \% \\
57 / 267 ; 21.3 \% \\
34 / 267 ; 12.7 \%\end{array}$ & $\begin{array}{l}6.31 \pm 1.70 \\
16 / 45 ; 35.6 \% \\
23 / 45 ; 51.1 \% \\
35 / 45 ; 77.8 \% \\
41 / 45 ; 91.1 \% \\
12 / 45 ; 26.7 \% \\
5 / 45 ; 11.1 \% \\
14 / 45 ; 31.1 \% \\
15 / 45 ; 33.3 \% \\
8 / 45 ; 17.8 \%\end{array}$ & $\begin{array}{l}7.98 \pm 3.58 \\
160 / 2 \mid 4 ; 74.8 \% \\
83 / 2 \mid 4 ; 38.8 \% \\
30.37 \pm 24.90 \\
6.66 \pm 1.26 \\
48 / 2 \mid 6 ; 22.2 \% \\
58 / 2 \mid 6 ; 26.9 \% \\
147 / 2 \mid 6 ; 68.1 \% \\
17|/ 2| 6 ; 79.2 \% \\
3|/ 2| 6 ; 14.4 \% \\
17 / 2 \mid 6 ; 7.9 \% \\
26 / 2 \mid 6 ; 12.0 \% \\
4|/ 2| 6 ; 19.0 \% \\
37 / 2 \mid 6 ; 12.0 \%\end{array}$ & $\begin{array}{l}t(259)=-1.59, p=0.11 \\
\chi^{2}=3.58, p=0.06 \\
\chi^{2}=10.24^{* *}, R R=1.90 \\
\chi^{2}=1.67, p=0.20 \\
\chi^{2}=3.48, p=0.06 \\
\chi^{2}=4.10^{*}, R R=1.85 \\
\chi^{2}=0.51, p=0.48 \\
\chi^{2}=10.44^{* *}, R R=2.59 \\
\chi^{2}=4.55^{*}, R R=1.75 \\
\chi^{2}=1.08, p=0.30\end{array}$ \\
\hline Snoring & $81 / 265 ; 30.6 \%$ & $15 / 45 ; 33.3 \%$ & $63 / 214 ; 29.4 \%$ & $\chi^{2}=0.27, p=0.61$ \\
\hline Stop breathing & $13 / 265 ; 4.9 \%$ & $6 / 45 ; 13.3 \%$ & $7 / 214 ; 3.3 \%$ & $\chi^{2}=7.90 *, \mathrm{RR}=4.03$ \\
\hline Woken up gasping for air & 24/265; $9.1 \%$ & II/45; $24.4 \%$ & $|3 / 2| 4 ; 6.1 \%$ & $\chi^{2}=14.92^{* * *}, \mathrm{RR}=4.00$ \\
\hline
\end{tabular}

Notes: Poverty $=$ annual household income $<\$ 20,000$. p represents statistical significance level of non-significant findings. Significant results are demarcated by $* 0.05$, $* * p<0.01$, ***p $<0.001$.

Abbreviations: BMI, body mass index $\left(\mathrm{kg} / \mathrm{m}^{2}\right)$, derived from electronic medical records; M, mean; SD, standard deviation; ISI, insomnia severity index; PSQI, Pittsburgh sleep quality index. t-statistic for comparison of independent groups; $d$, Cohen's d. $\chi^{2}$ represents chi-square; RR, rate ratio.

among women in poverty relative to those above the poverty line, indicating poorer global sleep quality for pregnant women in poverty (Cohen's $\mathrm{d}=0.45$ ). Notably, women in poverty were $72 \%$ more likely to score in the PSQI $>8$ range than those not in poverty. Despite higher rates of insomnia and sleep disturbance for women in poverty, no group difference in sleep aid use was observed $(\mathrm{p}=0.30)$.

In exploring different factors associated with sleep disturbance on $\geq 3$ nights per week (Table 2), women in 
poverty, relative to those above the poverty line, were more likely to endorse trouble sleeping due to difficulty falling asleep $(\mathrm{RR}=1.90)$, inability to breathe comfortably $(\mathrm{RR}=1.85)$, having bad dreams $(\mathrm{RR}=2.59)$, and pain $(R R=1.75)$. Average nightly sleep duration $(p=0.11)$ did not differ based on poverty status, although women in poverty had greater sleep discomfort (Cohen's d=0.68).

Sleep-related breathing issues were more commonly reported by women in poverty (Table 2 ), including higher rates of waking up gasping for air $(R R=4.03)$ and trouble sleeping due to inability to breathe comfortably $(R R=1.85)$.

\section{Racial Disparities In Prenatal Sleep: Comparing White Vs Black Pregnant Women}

Pregnant women identifying as white or black were well represented in this study and were thus appropriate for analysis (see Table 3 for full results). Black pregnant women were 4.44 times more likely to be in poverty than white pregnant women. BMI before pregnancy and during pregnancy were both higher among black women.

Insomnia symptoms and rates were higher among black pregnant women than for those identifying as white (Table 3). PSQI scores were also higher among black women (Cohen's d=0.36), who were $75 \%$ more likely to score in the PSQI $>8$ range than white women. In exploring different factors associated with sleep disturbance on $\geq 3$ nights per week, black women were more likely to report difficulty falling asleep $(R R=1.57)$ and inability to breathe comfortably $(R R=1.92)$. No racial differences in sleep aid use were observed $(p=0.46)$.

Black pregnant women reported sleeping 43 fewer minutes per night and were twice as likely to report sleeping $<6 \mathrm{hrs} /$ night compared to white women $(\mathrm{RR}=2.21)$. Black women also reported higher rates of waking up gasping for air $(\mathrm{RR}=2.57)$ and greater discomfort (Cohen's $\mathrm{d}=0.36$ ), whereas no group differences were found for snoring $(\mathrm{p}=0.12)$ or stopping breathing during sleep $(\mathrm{p}=0.05)$.

\section{Obesity-Related Disparities In Prenatal Sleep}

We then compared women based on a BMI cutoff of $\geq 35$ (i.e., class II-III obesity) regarding pre-pregnancy and during pregnancy measurements. Pre-pregnancy BMI better differentiated between women with good vs poor sleep in pregnancy. Thus, we present data for pre-pregnancy obesity here in Table 4, whereas data for pregnancy obesity can be found in Supplementary Table 3.

Obese women prior to pregnancy reported greater insomnia severity and higher rates of clinically severe insomnia (ISI $\geq 15$ ) than women whose pre-pregnancy BMI was $<35$ (Table 4). Similarly, obese women reported greater global sleep disturbance, were $67 \%$ more likely to score in the PSQI $>8$ range, and were twice as likely to use sleep aids $(\mathrm{RR}=2.38)$ as compared to non-obese women before pregnancy.

In exploring different factors associated with sleep disturbance on $\geq 3$ nights per week (Table 4), obese women attributed sleep difficulties to waking up during the night or early morning $(\mathrm{RR}=1.33)$ and needing to use the bathroom $(\mathrm{RR}=1.21)$.

Obese women slept 47 mins fewer per night and were more than twice as likely to sleep $<6 \mathrm{hrs}$ at night $(\mathrm{RR}=2.18)$ compared to women with pre-pregnancy BMI $<35$ (Table 4). Rates of self-reported snoring $(\mathrm{RR}=1.98)$ and stopping breathing during sleep $(R R=3.24)$ were higher among obese women, who also reported greater discomfort during sleep $(\mathrm{d}=0.43)$.

\section{Specificity Of Associations Among Poverty, Race, Class II-III Obesity, And Sleep}

Lastly, we regressed sleep outcomes of clinical interest (insomnia symptoms, sleep duration, SDB symptoms, sleep aid use) onto poverty status, race (white vs black), and class II-III obesity to identify independent associations between sleep parameters and these cooccurring phenomena. We tested multivariate linear regression for continuous outcomes and multivariate logistic regression for binary outcomes. We considered age as a potential covariate, but analyses showed that age was not associated with any of the sleep outcomes, likely due to restriction of range in this pregnant sample (20-44 years).

When controlling for the effects of race and BMI, multivariate regression models revealed that poverty was independently related to greater insomnia symptoms and greater odds of endorsing sleep onset insomnia, nightmare-related sleep disturbance, and breathing-related sleep difficulties (see Table 5 for full results). Race, however, was only related to sleep duration when controlling for effects related to poverty and class II-III obesity. Specifically, black women slept 31 fewer minutes than white women. Women who were obese before 
Table 3 Comparing Sleep Parameters Between Black And White Pregnant Women

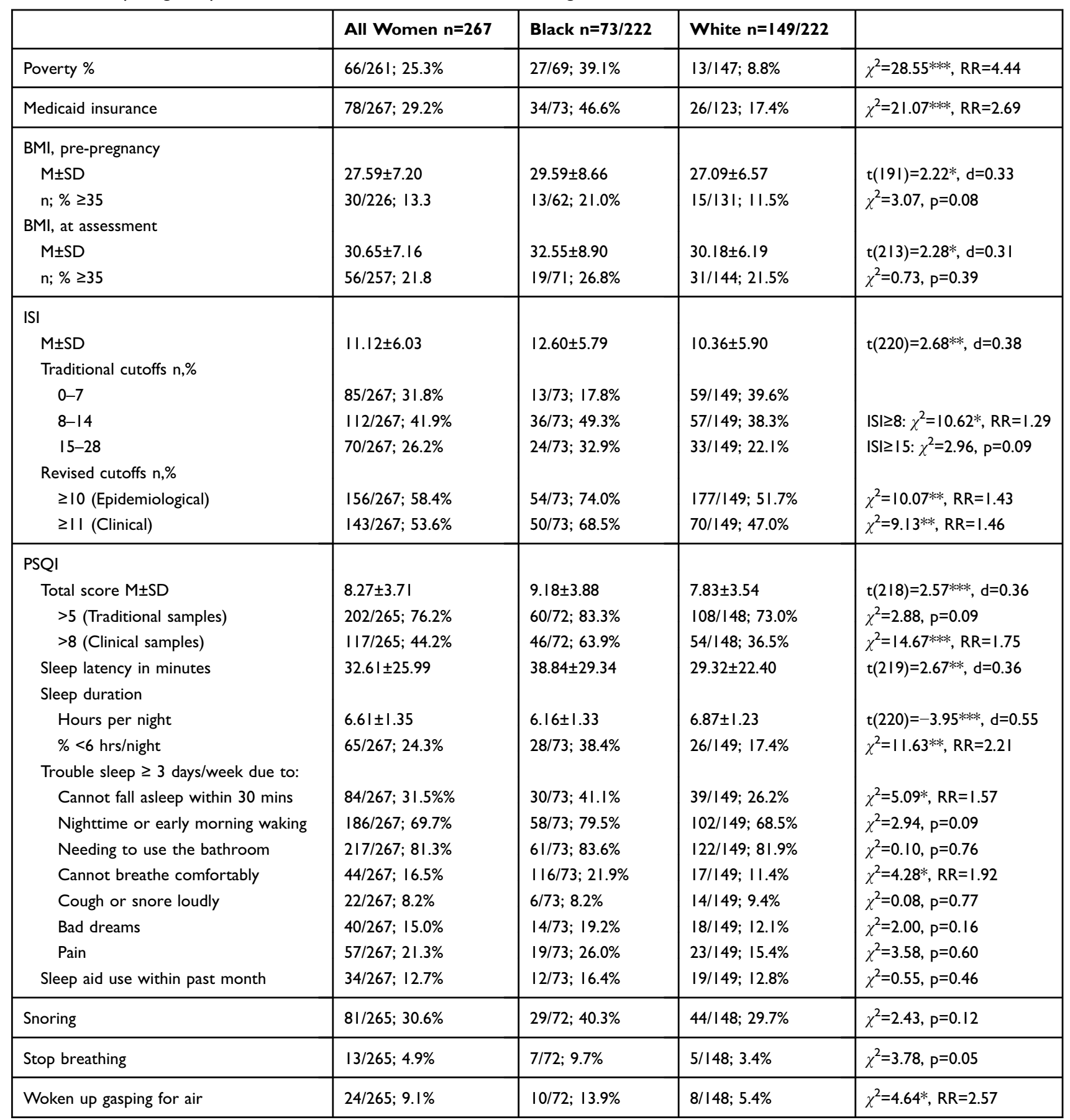

Notes: Poverty $=$ annual household income $<\$ 20,000$. p represents statistical significance level of non-significant findings. Significant results are demarcated by $* p<0.05$, $* * p<0.01$, *** $p<0.001$.

Abbreviations: BMI, body mass index ( $\mathrm{kg} / \mathrm{m} 2)$, derived from electronic medical records; M, mean; SD, standard deviation; ISI, insomnia severity index; PSQI, Pittsburgh sleep quality index. t-statistic for comparison of independent groups. $d$, Cohen's $d$. $\chi^{2}$ represents chi-square; RR, rate ratio.

pregnancy reported poorer global sleep quality, shorter sleep duration (by 41 minutes), and greater sleep difficulties related to snoring, relative to women whose prepregnancy BMI was $<35$. Notably, class II-III obesity before pregnancy was associated with greater odds of sleep aid use during pregnancy (Odds Ratio $[\mathrm{OR}]=2.64$, $\mathrm{p}<0.05)$ while controlling for the effects of race and poverty.

\section{Discussion}

In a sample of 267 pregnant women from Metro Detroit, we characterized sleep habits and quantitative parameters 
Table 4 Comparing Sleep Parameters Between Women Pre-Pregnancy BMI $\geq 35$ Vs BMI < 35

\begin{tabular}{|c|c|c|c|c|}
\hline & All Women $n=267$ & BMI $\geq 35 n=30 / 226$ & BMI $<35 n=196 / 226$ & \\
\hline \multicolumn{5}{|l|}{ ISI } \\
\hline$M \pm S D$ & $11.12 \pm 6.03$ & $|3.50 \pm 6.1|$ & $10.60 \pm 6.01$ & $t(224)=2.46^{*}, d=0.46$ \\
\hline \multicolumn{5}{|l|}{ Traditional cutoffs n, $\%$} \\
\hline $0-7$ & $85 / 267 ; 31.8 \%$ & $8 / 30 ; 26.7 \%$ & $68 / 196 ; 34.7 \%$ & \\
\hline $8-14$ & $112 / 267 ; 41.9 \%$ & $8 / 30 ; 26.7 \%$ & $82 / 196 ; 41.8 \%$ & $|S| \geq 8: \chi^{2}=0.75, p=0.39$ \\
\hline $15-28$ & $70 / 267 ; 26.2 \%$ & $14 / 30 ; 46.7 \%$ & $46 / 196 ; 23.5 \%$ & $|S| \geq \mid 5: \chi^{2}=7.18^{* *}, \mathrm{RR}=1.99$ \\
\hline \multicolumn{5}{|l|}{ Revised cutoffs n, \% } \\
\hline$\geq 10$ (Epidemiological) & I56/267; 58.4\% & $21 / 30 ; 70.0 \%$ & $105 / 196 ; 53.6 \%$ & $\chi^{2}=2.85, p=0.09$ \\
\hline$\geq I I$ (Clinical) & $143 / 267 ; 53.6 \%$ & $20 / 30 ; 66.7 \%$ & $96 / 196 ; 49.0 \%$ & $\chi^{2}=3.26, p=0.07$ \\
\hline \multicolumn{5}{|l|}{ PSQI } \\
\hline Total score $\mathrm{M} \pm \mathrm{SD}$ & $8.27 \pm 3.71$ & $10.87 \pm 4.32$ & $7.94 \pm 3.63$ & $t(222)=4.00 * * *, d=0.73$ \\
\hline$>5$ (Traditional samples) & $202 / 265 ; 76.2 \%$ & $24 / 30 ; 80.0 \%$ & $145 / 194 ; 74.7 \%$ & $\chi^{2}=0.39, p=0.53$ \\
\hline >8 (Clinical samples) & $117 / 265 ; 44.2 \%$ & $21 / 30 ; 70.0 \%$ & $81 / 194 ; 41.8 \%$ & $\chi^{2}=8.36 * *, R R=1.67$ \\
\hline Sleep latency in minutes & $32.6 I \pm 25.99$ & $41.83 \pm 28.45$ & $30.90 \pm 24.91$ & $t(223)=2.20 *, d=0.41$ \\
\hline \multicolumn{5}{|l|}{ Sleep duration } \\
\hline Hours per night & $6.61 \pm 1.35$ & $5.93 \pm 1.55$ & $6.71 \pm 1.29$ & $t(224)=-2.99 * *, d=0.55$ \\
\hline$\%<6$ hrs $/$ night & $65 / 267 ; 24.3 \%$ & I4/30; $46.7 \%$ & $42 / 196 ; 21.4 \%$ & $\chi^{2}=8.89 * *, \mathrm{RR}=2.18$ \\
\hline \multicolumn{5}{|l|}{ Trouble sleep $\geq 3$ days/week due to: } \\
\hline Cannot fall asleep within 30 mins & $84 / 267 ; 31.5 \% \%$ & $13 / 30 ; 43.3 \%$ & $58 / 196 ; 29.6 \%$ & $\chi^{2}=2.28, p=0.13$ \\
\hline Nighttime or early morning waking & $186 / 267 ; 69.7 \%$ & $27 / 30 ; 90.0 \%$ & $133 / 196 ; 67.9 \%$ & $\chi^{2}=6.17^{*}, \mathrm{RR}=1.33$ \\
\hline Needing to use the bathroom & $217 / 267 ; 81.3 \%$ & $29 / 30 ; 96.7 \%$ & $156 / 196 ; 79.6 \%$ & $\chi^{2}=5.1 I^{*}, \mathrm{RR}=1.21$ \\
\hline Cannot breathe comfortably & $44 / 267 ; 16.5 \%$ & $8 / 30 ; 26.7 \%$ & $32 / 196 ; 16.3 \%$ & $\chi^{2}=1.91, p=0.17$ \\
\hline Cough or snore loudly & $22 / 267 ; 8.2 \%$ & $2 / 30 ; 6.7 \%$ & $17 / 196 ; 8.7 \%$ & $\chi^{2}=0.14, p=0.71$ \\
\hline Bad dreams & $40 / 267 ; 15.0 \%$ & $7 / 30 ; 23.3 \%$ & $28 / 196 ; 14.3 \%$ & $\chi^{2}=1.63, p=0.20$ \\
\hline Pain & $57 / 267 ; 21.3 \%$ & $7 / 30 ; 23.3 \%$ & $41 / 196 ; 20.9 \%$ & $\chi^{2}=0.09, p=0.76$ \\
\hline Sleep aid use within past month & $34 / 267 ; 12.7 \%$ & $8 / 30 ; 26.7 \%$ & $22 / 196 ; 11.2 \%$ & $\chi^{2}=5.39 *, \mathrm{RR}=2.38$ \\
\hline Snoring & $81 / 265 ; 30.6 \%$ & $17 / 30 ; 56.7 \%$ & $56 / 195 ; 28.7 \%$ & $\chi^{2}=9.27 * *, \mathrm{RR}=1.98$ \\
\hline Stop breathing & $13 / 265 ; 4.9 \%$ & $4 / 30 ; 13.3 \%$ & $8 / 195 ; 4.1 \%$ & $\chi^{2}=4.39 *, R R=3.24$ \\
\hline Woken up gasping for air & 24/265; $9.1 \%$ & $2 / 30 ; 6.7 \%$ & $16 / 195 ; 8.2 \%$ & $\chi^{2}=0.08, p=0.77$ \\
\hline
\end{tabular}

Notes: $p$ represents statistical significance level of non-significant findings. Significant results are demarcated by $* p<0.05$. $* * p<0.0 \mathrm{I} . * * *<<0.00 \mathrm{I}$.

Abbreviations: BMI, body mass index $\left(\mathrm{kg} / \mathrm{m}^{2}\right)$, derived from electronic medical records; $\mathrm{M}$, mean; SD, standard deviation; ISI, insomnia severity index; PSQI, Pittsburgh sleep quality index. t-statistic for comparison of independent groups; $d$, Cohen's $d$. $\chi^{2}$ represents chi-square; RR, rate ratio.

and identified sleep disparities related to poverty, race, and class II-III obesity. Over three-quarters of the women in our study were classified as having significant sleep disturbance on a commonly used and standardized measure of global sleep quality. When examining different sleep health domains: over half of the sample screened positive for clinically significant insomnia symptoms, a quarter of the sample reported short sleep ( $<6 \mathrm{hrs} /$ night), and nearly one-third of the women reported snoring. Critically, three groups of pregnant women were identified as having particularly elevated rates of sleep issues: women in poverty, women who self-identified as non-Hispanic black, and women with class II-III obesity, particularly before pregnancy. These results offer preliminary evidence that women at risk for prenatal sleep issues may be identifiable early in pregnancy based on routinely assessed sociodemographic characteristics in prenatal care.

\section{Sleep Habits And Problems In Mid-To- Late Pregnancy Insomnia And Short Sleep}

Over half of our sample screened positive for clinically significant insomnia, but only 9 women reported an insomnia diagnosis. This suggests that upwards of $95 \%$ of the cases go undetected through mid and late pregnancy, which is of serious concern given the negative perinatal outcomes associated with insomnia and insufficient sleep, ${ }^{11-19}$ particularly since these women were actively engaged in routine prenatal care allowing opportunity for detection. Consistent with epidemiological and obstetric clinic data, ${ }^{1,10}$ sleep 
Table 5 Regressing Sleep Parameters On BMI, Race, And Poverty Status

\begin{tabular}{|c|c|c|c|c|}
\hline Outcome & Predictors & & & \\
\hline Linear Regression Models & & $\mathbf{b}$ & $\beta$ & $\mathbf{p}$ \\
\hline $\begin{array}{l}I S I \\
F(3, \mid 83)=5.14, p<0.01\end{array}$ & $\begin{array}{l}\text { Poverty } \\
\text { Black } \\
\text { BMI } \geq 35\end{array}$ & $\begin{array}{l}2.84 \\
1.32 \\
1.91\end{array}$ & $\begin{array}{l}0.18 \\
0.10 \\
0.11\end{array}$ & $\begin{array}{l}0.03 \\
0.20 \\
0.12\end{array}$ \\
\hline $\begin{array}{l}\text { PSQI } \\
F(3,|8|)=6.17, p<0.01\end{array}$ & $\begin{array}{l}\text { Poverty } \\
\text { Black } \\
\text { BMI } \geq 35\end{array}$ & $\begin{array}{l}1.16 \\
0.56 \\
2.58\end{array}$ & $\begin{array}{l}0.12 \\
0.07 \\
0.24\end{array}$ & $\begin{array}{l}0.15 \\
0.39 \\
<0.01\end{array}$ \\
\hline $\begin{array}{l}\text { Sleep Duration } \\
F(3,183)=5.64, p<0.01\end{array}$ & $\begin{array}{l}\text { Poverty } \\
\text { Black } \\
\text { BMI } \geq 35\end{array}$ & $\begin{array}{l}-0.13 \\
-0.51 \\
-0.68\end{array}$ & $\begin{array}{l}-0.04 \\
-0.18 \\
-0.19\end{array}$ & $\begin{array}{l}0.64 \\
0.02 \\
0.01\end{array}$ \\
\hline Logistic Regression Models & & $b$ & OR $(95 \% \mathrm{Cl})$ & $\mathrm{P}$ \\
\hline $\begin{array}{l}\text { Sleep Onset Insomnia } \\
\chi^{2}=7.67, p=0.05\end{array}$ & $\begin{array}{l}\text { Poverty } \\
\text { Black } \\
\text { BMI } \geq 35\end{array}$ & $\begin{array}{l}1.03 \\
0.05 \\
0.25\end{array}$ & $\begin{array}{l}2.81(1.16,6.78) \\
- \\
-\end{array}$ & $\begin{array}{l}0.02 \\
0.90 \\
0.61\end{array}$ \\
\hline $\begin{array}{l}\text { Sleep Maintenance Insomnia } \\
\chi^{2}=7.64, p=0.08\end{array}$ & $\begin{array}{l}\text { Poverty } \\
\text { Black } \\
\text { BMI } \geq 35\end{array}$ & $\begin{array}{l}0.18 \\
0.49 \\
1.12\end{array}$ & $\begin{array}{l}- \\
- \\
-\end{array}$ & $\begin{array}{l}0.74 \\
0.26 \\
0.08\end{array}$ \\
\hline $\begin{array}{l}\text { Breathing-related sleep disturbance } \\
\chi^{2}=9.72, p=0.02\end{array}$ & $\begin{array}{l}\text { Poverty } \\
\text { Black } \\
\text { BMI } \geq 35\end{array}$ & $\begin{array}{l}1.62 \\
0.58 \\
-0.07\end{array}$ & $\begin{array}{l}5.06(1.99,12.86) \\
- \\
-\end{array}$ & $\begin{array}{l}<0.01 \\
0.40 \\
0.91\end{array}$ \\
\hline $\begin{array}{l}\text { Nightmare-related sleep disturbance } \\
\chi^{2}=9.79, p=0.02\end{array}$ & $\begin{array}{l}\text { Poverty } \\
\text { Black } \\
\text { BMI } \geq 35\end{array}$ & $\begin{array}{l}1.31 \\
0.25 \\
0.04\end{array}$ & $\begin{array}{l}3.72(1.34,10.31) \\
- \\
-\end{array}$ & $\begin{array}{l}0.01 \\
0.61 \\
0.92\end{array}$ \\
\hline $\begin{array}{l}\text { Pain-related sleep disturbance } \\
\chi^{2}=6.32, p=0.10\end{array}$ & $\begin{array}{l}\text { Poverty } \\
\text { Black } \\
\text { BMI } \geq 35\end{array}$ & $\begin{array}{l}0.80 \\
0.45 \\
-0.27\end{array}$ & $\begin{array}{l}- \\
- \\
-\end{array}$ & $\begin{array}{l}0.10 \\
0.30 \\
0.63\end{array}$ \\
\hline $\begin{array}{l}\text { Snoring } \\
\chi^{2}=7.93, p<0.05\end{array}$ & $\begin{array}{l}\text { Poverty } \\
\text { Black } \\
\text { BMI } \geq 35\end{array}$ & $\begin{array}{l}-0.28 \\
0.53 \\
0.97\end{array}$ & $\begin{array}{l}- \\
- \\
2.64(1.14,6.15)\end{array}$ & $\begin{array}{l}0.55 \\
0.15 \\
0.02\end{array}$ \\
\hline $\begin{array}{l}\text { Sleep aid use } \\
\chi^{2}=5.27, p=0.15\end{array}$ & $\begin{array}{l}\text { Poverty } \\
\text { Black } \\
\text { BMI } \geq 35\end{array}$ & $\begin{array}{l}-0.11 \\
0.49 \\
0.97\end{array}$ & $\begin{array}{l}- \\
- \\
2.64(1.01,6.91)\end{array}$ & $\begin{array}{l}0.84 \\
0.30 \\
<0.05\end{array}$ \\
\hline
\end{tabular}

Notes: Poverty $=$ annual household income $<\$ 20,000$. Sleep duration, sleep onset insomnia, sleep maintenance insomnia, nightmare-related sleep disturbance, pain-related sleep disturbance, and sleep aid use were all derived and dichotomized based on responses to individual items on the PSQI. Subjects who endorsed trouble sleeping $\geq 3$ days/ week due to these issues were categorized as positive cases, whereas subjects who experienced these symptoms <3 days/week were categorized as negative cases. F-statistic represents overall linear regression model fit. $\chi^{2}$ represents overall logistic regression model fit. $b=$ unstandardized regression coefficients. $\beta=$ standardized regression coefficient for linear model predictors. $\mathrm{p}=$ statistical significance.

Abbreviations: BMI, body mass index $\left(\mathrm{kg} / \mathrm{m}^{2}\right)$, derived from electronic medical records. BMI $\geq 35$ represents class II-III obesity; ISI, insomnia severity index; PSQI, Pittsburgh sleep quality index; OR, odds-ratio; $95 \% \mathrm{Cl}, 95 \%$ confidence interval. 
maintenance insomnia was the primary insomnia complaint, although sleep-onset symptoms were also elevated compared to the general population. Notably, no particular insomnia phenotype appears to dominate clinical presentations of the broader female insomnia population in the $\mathrm{US}^{47}$ (except that sleep maintenance difficulty is also the cardinal feature of menopausal insomnia ${ }^{48}$ ).

Pregnant women were 1.5 times more likely to report short sleep relative to observations in a prior study of adults recruited from the same geographical area $(24 \%$ in pregnant women vs $16 \%$ in broader adult population in Metro Detroit ${ }^{28}$ ). This is especially concerning given the high rates of insomnia in our sample. Research shows that short sleep augments the pathogenicity of insomnia such that individuals with both insomnia and short sleep are at higher risk for psychiatric illness, cardiovascular disease, and metabolic disorders than those who have short sleep or insomnia alone in non-pregnant samples, particularly when short sleep is objectively assessed. ${ }^{28,44}$ It is unclear, however, the extent to which subjects had short sleep due to exogenous factors (i.e., environmental factors such as insufficient sleep opportunity) vs endogenous factors (i.e., inability to sleep longer despite sufficient opportunity). This is an important distinction as endogenously and exogenously shortened sleep may differentially affect perinatal outcomes and because targets for intervention would differ. It is also notable that half of the women in our study reported napping during the day, which may represent compensatory behavior for insufficient sleep, yet it is unknown whether napping counteracts the effects of short nighttime sleep or is a contributing factor to poor nocturnal sleep.

\section{Sleep-Related Breathing Difficulties}

The women in our study endorsing SDB symptoms far outnumbered those who reported a diagnosis of SDB. Only $3.0 \%$ of the women reported an OSA diagnosis, which is much lower than estimated prevalence rates of $8.3 \%$ in the 2 nd trimester ${ }^{9}$ and $26.7 \%$ in the 3 rd trimester. ${ }^{8}$ Although certainly not all pregnant women who endorse snoring or other breathing difficulties necessarily have $\mathrm{SDB}$, our data coupled with prevalence rates suggest that many cases of SDB appear to go undetected or undiagnosed through mid and late pregnancy. Importantly, even when pregnant women do not undergo PSG to test for sleeprelated breathing disorders, self-reported snoring itself has been linked to serious perinatal complications. ${ }^{4,6,7,20,21}$ Clinical settings and research studies should endeavor to using cutting-edge screening tools to detect probably SDB in pregnant women, which may include consideration of multiple factors such as age, BMI, and frequent snoring. ${ }^{49}$

\section{Poverty-Related Disparities In Prenatal Sleep}

At $17.2 \%$ in our sample, estimated poverty rates in our study were higher than the US Census Bureau's most recent nationwide poverty estimate of $12.3 \%{ }^{50}$ Further, 3 out of every 10 women in our study were on Medicaid, which was strongly linked to poverty status. Several sleep problems were elevated for women in poverty, many of which have been linked to stress in the broader insomnia literature. Insomnia symptom severity and rates were much higher for pregnant women in poverty compared to those above the poverty line. This is consistent with prior research showing that poor sleep is strongly associated with poverty and financial strain. ${ }^{24-26}$ Women in poverty were twice as likely to endorse symptoms of sleep-onset insomnia, although sleep maintenance insomnia did not differ between groups. Women in poverty were also at greater risk of endorsing trouble sleeping due to bad dreams. As sleep onset insomnia is characterized by stress dysregulation in the form of presleep cognitive arousal, ${ }^{51,52}$ this disparity may be influenced in part to higher levels of nocturnal rumination and/or worry among women living in poverty. Indeed, presleep cognitions often reappear during REM dreaming, ${ }^{53}$ thus ruminating or worrying about financial hardships and other low SES-related stressors may also contribute to higher rates of nightmare-related sleep difficulties. Importantly, when controlling for the effects of class II-III obesity and race, poverty remained independently associated with insomnia severity, sleep onset insomnia, and nightmarerelated sleep disturbance. Future studies should investigate whether stress mediates the association between poverty and sleep disturbance, which could be helpful in identifying therapeutic targets to reduce risk for poor sleep in marginalized pregnant women.

Women in poverty, relative to those above the poverty line, also endorsed higher rates of sleep disturbance due to difficulty breathing, stopping breathing during sleep, and waking up gasping for air. When controlling for class II-III obesity and race, poverty status remained a significant risk factor for breathing-related sleep disturbance. However, quite notably, snoring did not differ between income groups. As such, our data only partially support women in poverty as being more likely to endorse clinical signs of sleep breathing difficulties. Even so, a recent large-scale epidemiological study of US adults found that, although poverty was 
associated with several sleep problems, this was not the case when controlling for other aspects of socioeconomical status. ${ }^{45}$ Thus, it is possible that poverty in our study would no longer correspond to breathing-related sleep disturbance when accounting for additional economic factors.

\section{Racial Disparities In Prenatal Sleep: Comparing White Vs Black Pregnant Women}

Race-related differences in sleep were arguably most notable for being wide-ranging, until statistically controlling for the effects of class II-III obesity and poverty. That is, black nonHispanic women, relative to white non-Hispanic women, endorsed greater insomnia symptoms, sleep onset insomnia, sleep-related breathing problems, and shorter sleep duration. However, when controlling for the effects of class II-III obesity and poverty, the only difference between white and black pregnant women regarding aspects of sleep we measured was sleep duration. That is, black women reported shorter sleep duration than white women, even when controlling for BMI and poverty status. This finding is highly consistent with prior research utilizing subjective and objective sleep assessments showing that black people sleep shorter than white people in the US. ${ }^{28-30}$ Yet, all of the other sleep problems that were elevated among black women in our study disappeared when controlling for BMI and income. Relative to whites in our study, black women were 4.44 times more likely to be in poverty and had higher BMI prior to and during pregnancy. Thus, it is of little surprise that race-related differences in socioeconomical status and overall health appear to contribute to many of the racial disparities in sleep.

\section{Class II-III Obesity And Disparities In Prenatal Sleep}

Pre-pregnancy BMI was a more robust predictor of prenatal sleep than BMI during pregnancy, which suggests that pre-pregnancy BMI is a superior indicator of overall health. Women who were severely obese $(\mathrm{BMI} \geq 35$ ) before pregnancy later reported greater sleep maintenance insomnia symptoms, use of sleep aids during pregnancy, snoring, stopping breathing during sleep, and trouble sleeping related frequent need to use the bathroom at night. When controlling for the effects of race and poverty status, class II-III obesity was related to greater global sleep disturbance via the PSQI, snoring, sleep aid use, and shorter sleep duration. These data suggest that BMI before pregnancy (and potentially even in the early stages of pregnancy before notable weight gain) may be a marker of risk for sleep problems and/or their exacerbation during pregnancy, particularly regarding difficulties related to breathing and the use of sleep aids. This result supports a previous finding by our team that pre-pregnancy obesity is related to snoring during pregnancy. ${ }^{21}$ Further, the association between obesity and SDB symptoms is consistent with evidence that high BMI is the most robust risk factor for OSA in non-pregnant women. ${ }^{32}$ However, BMI has been shown to be a poor predictor of UARS in nonpregnant women. ${ }^{54}$ Research is needed to better identify early signs of risk of UARS in pregnant women.

Notably, the PSQI is a global measure of sleep quality and disturbance as it assesses insomnia, breathing-related problems, sleep duration, and other aspects of sleep health. Thus, if a patient screens positive on the PSQI, the questionnaire should be flagged and further evaluated at the item-level to better understand the source of sleeping difficulties experienced.

\section{Sleep Aid Use In Pregnancy}

Sleep aid use was reported by $12.7 \%$ of the women in our study and obesity prior to pregnancy was associated with greater likelihood using sleep aids later in pregnancy. Given that our study and prior research have shown that perinatal obesity is most closely linked to $\mathrm{SDB},{ }^{8,11,20}$ it is possible that obese women in our study were more likely to have taken sleep aids to combat symptoms of SDB, which may masquerade as insomnia (e.g., sleep breathing difficulties leading to awakenings). Given that some sedative hypnotics with widespread central nervous system suppression can negatively affect breathing during sleep, ${ }^{55}$ using sleep aids could potentially worsen SDB in pregnant women. Given the high rates of sleep disturbance and insomnia in this population, identifying pharmacological and nonpharmacological behavioral treatment options for pregnant women that are both safe and effective for acute and/or chronic use holds immense potential and is a critical need for improving quality of life and emotional health for pregnant women.

\section{Limitations}

Our study findings should be interpreted in the context of important methodological limitations. The study was cross-sectional and pre-pregnancy sleep parameters are unknown. Thus, we cannot determine the directionality or causality of associations based on our data. Further, data are 
mixed regarding whether sleep quality changes drastically across pregnancy; ${ }^{1,3,5,12,56}$ therefore, we cannot determine the extent to which high rates of sleep disturbance in our sample represent changes from pre-pregnancy baseline. Along these lines, if sleep quality does indeed change across pregnancy, then our data best reflect presentations for pregnant women in mid and late pregnancy, and thus may not accurately reflect sleep and related factors in earlier stages of pregnancy. Additionally, our sample does not likely represent the broader US population of pregnant women. As our study derived its sample from the Metro Detroit area, rates of insomnia, snoring, and other sleep phenotypes may better reflect populations with similar demographic characteristics. By extension, only women identifying as non-Hispanic white and non-Hispanic black were sufficiently represented to be included in racial disparity analyses. Thus, race-related differences pertaining to Hispanic, Latinx, Asian, and other groups were not explored here. Additionally, as the study was web-based, we were unable to include potential participants without reliable internet access, many of whom may have low socioeconomic position.

Notably, all sleep and most health (e.g., hypertension, diabetes, pre-eclampsia) data were self-reported. While patient impressions of their sleep are uniquely important, subjective impressions on sleep duration and sleep breathing issues can be inconsistent with objective data and even partner reports. Indeed, emerging evidence suggests that screening for SDB should include multiple factors including BMI, age, and frequent snoring. When possible, future research should consider using objective sleep assessments and partner reports of sleep. Similarly, health-care providers may seek partner input on patient sleep (e.g., to determine snoring) when available and appropriate. Lastly, in an effort to be comprehensive, the present study involved multiple statistical analyses. As each test performed increases chances of type I errors, these results of this exploratory project should be replicated in future projects examining sleep disparities in pregnant women for confirmation. Despite the heightened risk for type I errors for multiple analyses, it is important to emphasize that our sleep disparity findings are consistent with results in non-pregnant adult populations, as outlined above.

\section{Conclusions}

Insomnia and sleep-related breathing problems disproportionately affect pregnant women in poverty, who self-identify as racially black, and are obese before pregnancy. Our findings may guide the generation of research ideas to prospectively investigate differential trajectories of sleep symptoms for marginalized populations. In addition, these populations of women may be targeted for prevention or early intervention. Pregnant women are typically involved in routine prenatal care with regular visits; thus, obstetricians and midwives have the opportunity to identify at-risk women and monitor sleep across pregnancy. Consideration should be given to placing greater emphasis on sleep health and monitoring during prenatal care in obstetrics clinics and to better educate patients on the signs and symptoms of sleep disorders. Future research is needed to examine what extent these health disparities pre-exist pregnancy vs develop gestationally.

\section{Abbreviations}

BMI, body mass index; EMR, electronic medical record; HST, home sleep test; ISI, insomnia severity index; OR, odds ratio; OSA, obstructive sleep apnea; PSG, polysomnography; PSQI, Pittsburgh sleep quality index; RCT, randomized controlled trial; RR, rate ratio; SDB, sleepdisordered breathing; SES, socioeconomic status; UARS, upper airway resistance syndrome.

\section{Ethics Approval}

Ethical approval was granted by the Henry Ford Health System internal review board. All procedures performed in studies involving human subjects were in accordance with the ethical standards of the institutional and/or national research committee and with the 1964 Helsinki declaration and its later amendments or comparable ethical standards. All volunteers provided informed consent prior to participation.

\section{Acknowledgments}

This study was funded by the American Academy of Sleep Medicine (198-FP-18; PI: Kalmbach). Dr. Cheng's effort was supported by the National Heart, Lung, \& Blood Institute (K23 HL13866, PI: Cheng). Dr. Drake's effort was supported in part by the National Institute of Nursing Research (R01 NR013959; PI: Drake).

\section{Author Contributions}

All authors contributed to the conception, design, acquisition of data, and/or analysis and interpretation of data. All authors contributed to the drafting and revising of the manuscript and have approved it for submission for publication.

\section{Disclosure}

Dr. Kalmbach has received research support from Merck \& Co. Dr. Roth has received research support from 
Aventis, Cephalon, Glaxo Smith Kline, Neurocrine, Pfizer, Sanofi, Schering-Plough, Sepracor, Somaxon, Syrex, Takeda, TransOral, Wyeth and Xenoport and has acted as a consultant for Abbott, Acadia, Acoglix, Actelion, Alchemers, Alza, Ancil, Arena, Astra Zeneca, Aventis, AVER, BMS, BTG, Cephalon, Cypress, Dove, Elan, Eli Lilly, Evotec, Forest, Glaxo Smith Kline, Hypnion, Impax, Intec, Intra-Cellular, Jazz, Johnson \& Johnson, King, Lundbeck, McNeil, Medici Nova, Merck \& Co., Neurim, Neurocrine, Neurogen, Novartis, Orexo, Organon, Prestwick, Procter-Gamble, Pfizer, Purdue, Resteva, Roche, Sanofi, Schering-Plough, Sepracor, Servier, Shire, Somaxon, Syrex, Takeda, TransOral, Vanda, Vivometrics, Wyeth, Yamanuchi, and Xenoport. Dr. Cheng has received research support from Harmony Biosciences. Dr. Drake has received research support from Merck \& Co., Eisai Co., Aladdin Dreamer, Jazz, Actelion, and Teva, and has served on speakers bureau for Merck \& Co. The authors declare no other financial or non-financial interests exist in this work.

\section{References}

1. Mindell JA, Cook RA, Nikolovski J. Sleep patterns and sleep disturbances across pregnancy. Sleep Med. 2015;16(4):483-488. doi:10.1016/j.sleep.2014.12.006

2. Hutchison BL, Stone PR, McCowan LM, Stewart AW, Thompson JM, Mitchell EA. A postal survey of maternal sleep in late pregnancy. $B M C$ Pregnancy Childbirth. 2012;12(1):144. doi:10.1186/1471-2393-12144

3. Facco FL, Kramer J, Ho KH, Zee PC, Grobman WA. Sleep disturbances in pregnancy. Obstet Gynecol. 2010;115(1):77-83. doi:10.1097/AOG.0b013e3181c4f8ec

4. Sarberg M, Svanborg E, Wiréhn A-B, Josefsson A. Snoring during pregnancy and its relation to sleepiness and pregnancy outcome-a prospective study. BMC Pregnancy Childbirth. 2014;14(1):15. doi:10.1186/1471-2393-14-15

5. Kızılırmak A, Timur S, Kartal B. Insomnia in pregnancy and factors related to insomnia. Sci World J. 2012;2012.

6. O'Brien LM, Bullough AS, Owusu JT, et al. Snoring during pregnancy and delivery outcomes: a cohort study. Sleep. 2013;36 (11):1625-1632. doi: $10.5665 /$ sleep.3112

7. O'brien LM, Bullough AS, Owusu JT, et al. Pregnancy-onset habitual snoring, gestational hypertension, and preeclampsia: prospective cohort study. Am J Obstet Gynecol. 2012;207(6):487. e481-487. e489.

8. Pien GW, Pack AI, Jackson N, Maislin G, Macones GA, Schwab RJ. Risk factors for sleep-disordered breathing in pregnancy. Thorax. 2014;69(4):371-377. doi:10.1136/thoraxjnl-2012-202718

9. Facco FL, Parker CB, Reddy UM, et al. Association between sleepdisordered breathing and hypertensive disorders of pregnancy and gestational diabetes mellitus. Obstet Gynecol. 2017;129(1):31. doi:10.1097/AOG.0000000000001805

10. Mindell JA, Jacobson BJ. Sleep disturbances during pregnancy. $J$ Obstet Gynecol Neonatal Nurs. 2000;29(6):590-597. doi:10.1111/ j.1552-6909.2000.tb02072.x

11. Reichner CA. Insomnia and sleep deficiency in pregnancy. Obstet Med. 2015;8(4):168-171. doi:10.1177/1753495X15600572
12. Palagini L, Gemignani A, Banti S, Manconi M, Mauri M, Riemann D. Chronic sleep loss during pregnancy as a determinant of stress: impact on pregnancy outcome. Sleep Med. 2014;15(8):853-859. doi:10.1016/j.sleep.2014.02.013

13. Okun ML, Kiewra K, Luther JF, Wisniewski SR, Wisner KL. Sleep disturbances in depressed and nondepressed pregnant women. Depress Anxiety. 2011;28(8):676-685. doi:10.1002/da.20828

14. Okun ML, Hall M, Coussons-Read ME. Sleep disturbances increase interleukin-6 production during pregnancy: implications for pregnancy complications. Reprod Sci. 2007;14(6):560-567. doi:10.1177/ 1933719107307647

15. Okun ML, Luther JF, Wisniewski SR, Wisner KL. Disturbed sleep and inflammatory cytokines in depressed and nondepressed pregnant women: an exploratory analysis of pregnancy outcomes. Psychosom Med. 2013;75(7):670. doi:10.1097/PSY.0b013e31829cc3e7

16. Palagini L, Cipollone G, Masci I, et al. Stress-related sleep reactivity is associated with insomnia, psychopathology and suicidality in pregnant women: preliminary results. Sleep Med. 2019;56:145-150. doi:10.1016/j.sleep.2019.01.009

17. Dørheim SK, Bjorvatn B, Eberhard-Gran M, Mazza M. Can insomnia in pregnancy predict postpartum depression? A longitudinal, population-based study. PLoS One. 2014;9(4):e94674. doi:10.1371/journal. pone.0094674

18. Swanson LM, Pickett SM, Flynn H, Armitage R. Relationships among depression, anxiety, and insomnia symptoms in perinatal women seeking mental health treatment. $J$ Womens Health. 2011;20 (4):553-558. doi:10.1089/jwh.2010.2371

19. Kalmbach DA, Cheng P, Ong JC, et al. Depression and suicidal ideation in pregnancy: exploring relationships with insomnia, short sleep, and nocturnal rumination. Sleep Med. 2019. doi:10.1016/j. sleep.2019.07.010

20. O’Brien LM, Bullough AS, Chames MC, et al. Hypertension, snoring, and obstructive sleep apnoea during pregnancy: a cohort study. BJOG. 2014;121(13):1685-1693. doi:10.1111/1471-0528.12885

21. O’Brien LM, Owusu JT, Swanson LM. Habitual snoring and depressive symptoms during pregnancy. BMC Pregnancy Childbirth. 2013;13(1):113. doi:10.1186/1471-2393-13-174

22. Louis J, Auckley D, Miladinovic B, et al. Perinatal outcomes associated with obstructive sleep apnea in obese pregnant women. Obstet Gynecol. 2012;120(5).

23. Pien GW, Schwab RJ. Sleep disorders during pregnancy. Sleep. 2004;27(7):1405-1417. doi:10.1093/sleep/27.7.1405

24. Patel NP, Grandner MA, Xie D, Branas CC, Gooneratne N. Sleep disparity" in the population: poor sleep quality is strongly associated with poverty and ethnicity. BMC Public Health. 2010;10(1):475. doi:10.1186/1471-2458-10-475

25. Grandner MA, Patel NP, Gehrman PR, et al. Who gets the best sleep? Ethnic and socioeconomic factors related to sleep complaints. Sleep Med. 2010;11(5):470-478. doi:10.1016/j.sleep.2009.10.006

26. Hall MH, Matthews KA, Kravitz HM, et al. Race and financial strain are independent correlates of sleep in midlife women: the SWAN sleep study. Sleep. 2009;32(1):73-82.

27. Stamatakis KA, Kaplan GA, Roberts RE. Short sleep duration across income, education, and race/ethnic groups: population prevalence and growing disparities during 34 years of follow-up. Ann Epidemiol. 2007;17(12):948-955. doi:10.1016/j.annepidem.2007.07.096

28. Kalmbach DA, Pillai V, Arnedt JT, Drake CL. DSM-5 insomnia and short sleep: comorbidity landscape and racial disparities. Sleep. 2016;39(12):2101-2111. doi:10.5665/sleep.6306

29. Whinnery J, Jackson N, Rattanaumpawan P, Grandner MA. Short and long sleep duration associated with race/ethnicity, sociodemographics, and socioeconomic position. Sleep. 2014;37(3):601-611. doi: $10.5665 /$ sleep. 3508

30. Petrov ME, Lichstein KL. Differences in sleep between black and white adults: an update and future directions. Sleep Med. 2016;18:74-81. doi:10.1016/j.sleep.2015.01.011 
31. Hale L, Do DP. Racial differences in self-reports of sleep duration in a population-based study. Sleep. 2007;30(9):1096-1103. doi:10.1093/ sleep/30.9.1096

32. Bixler EO, Vgontzas AN, Lin H-M, et al. Prevalence of sleep-disordered breathing in women: effects of gender. Am J Respir Crit Care Med. 2001;163(3):608-613. doi:10.1164/ajrccm.163.3.9911064

33. Louis JM, Auckley D, Sokol RJ, Mercer BM. Maternal and neonatal morbidities associated with obstructive sleep apnea complicating pregnancy. Am J Obstet Gynecol. 2010;202(3):261. e261-261. e265. doi:10.1016/j.ajog.2009.10.867

34. Bleich SN, Thorpe RJ, Sharif-Harris H, Fesahazion R, LaVeist TA. Social context explains race disparities in obesity among women. J Epidemiol Community Health. 2010;64(5):465-469. doi:10.1136/jech.2009.096297

35. Williams DR, Collins C. Racial residential segregation: a fundamental cause of racial disparities in health. Public Health Rep. 2001;116 (5):404. doi:10.1016/S0033-3549(04)50068-7

36. LaVeist TA. Disentangling race and socioeconomic status: a key to understanding health inequalities. J Urban Health. 2005;82(3):iii26iii34. doi:10.1093/jurban/jti061

37. Bastien $\mathrm{CH}$, Vallières A, Morin CM. Validation of the insomnia severity index as an outcome measure for insomnia research. Sleep Med. 2001;2(4):297-307.

38. Morin CM, Belleville G, Bélanger L, Ivers H. The insomnia severity index: psychometric indicators to detect insomnia cases and evaluate treatment response. Sleep. 2011;34(5):601-608. doi:10.1093/sleep/ 34.5.601

39. Buysse DJ, Reynolds III CF, Monk TH, Berman SR, Kupfer DJ. The pittsburgh sleep quality index: a new instrument for psychiatric practice and research. Psychiatry Res. 1989;28(2):193-213. doi:10.1016/0165-1781(89)90047-4

40. Carpenter JS, Andrykowski MA. Psychometric evaluation of the pittsburgh sleep quality index. J Psychosom Res. 1998;45(1):5-13. doi:10.1016/s0022-3999(97)00298-5

41. Fichtenberg NL, Putnam SH, Mann NR, Zafonte RD, Millard AE. Insomnia screening in postacute traumatic brain injury: utility and validity of the pittsburgh sleep quality index. Am J Phys Med Rehabil. 2001;80 (5):339-345. doi:10.1097/00002060-200105000-00003

42. Kalmbach DA, Conroy DA, Falk H, et al. Poor sleep is linked to impeded recovery from traumatic brain injury. Sleep. 2018;41(10): zsy147. doi:10.1093/sleep/zsy024
43. Fichtenberg NL, Zafonte RD, Putnam S, Mann NR, Millard AE. Insomnia in a post-acute brain injury sample. Brain Inj. 2002;16 (3):197-206. doi:10.1080/02699050110103940

44. Vgontzas AN, Fernandez-Mendoza J, Liao D, Bixler EO. Insomnia with objective short sleep duration: the most biologically severe phenotype of the disorder. Sleep Med Rev. 2013;17(4):241-254. doi:10.1016/j.smrv.2012.09.005

45. Grandner MA, Petrov MER, Rattanaumpawan P, Jackson N, Platt A, Patel NP. Sleep symptoms, race/ ethnicity, and socioeconomic position. J Clin Sleep Med. 2013;9(09):897-905. doi:10.5664/jcsm.2990

46. Chung F, Abdullah HR, Liao P. STOP-bang questionnaire: a practical approach to screen for obstructive sleep apnea. Chest. 2016;149 (3):631-638. doi:10.1378/chest.15-0903

47. Pillai V, Roth T, Drake CL. The nature of stable insomnia phenotypes. Sleep. 2015;38(1):127-138. doi:10.5665/sleep.4338

48. Drake CL, Kalmbach DA, Arnedt JT, et al. Treating chronic insomnia in postmenopausal women: a randomized clinical trial comparing cognitive-behavioral therapy for insomnia, sleep restriction therapy, and sleep hygiene education. Sleep. 2018;42(2):zsy217.

49. Louis JM, Koch MA, Reddy UM, et al. Predictors of sleep-disordered breathing in pregnancy. Am J Obstet Gynecol. 2018;218(5):521. e521-521. e512. doi:10.1016/j.ajog.2018.01.031

50. Poverty. 2019. Accessed March 20, 2019.

51. Harvey AG. Pre-sleep cognitive activity: a comparison of sleeponset insomniacs and good sleepers. Br J Clin Psychol. 2000;39 (3):275-286.

52. Pillai V, Drake CL. Sleep and repetitive thought: the role of rumination and worry in sleep disturbance. In: Babson KA, Feldner MT, editors. Sleep and Affect. London: Elsevier; 2015:201-225.

53. Riemann D, Spiegelhalder K, Nissen C, Hirscher V, Baglioni C, Feige B. REM sleep instability-a new pathway for insomnia? Pharmacopsychiatry. 2012;45(05):167-176. doi:10.1055/s-0031-1299721

54. Mohsenin V. Gender differences in the expression of sleep-disordered breathing: role of upper airway dimensions. Chest. 2001;120 (5):1442-1447. doi:10.1378/chest.120.5.1442

55. Guilleminault C. Benzodiazepines, breathing, and sleep. Am J Med. 1990;88(3):S25-S28. doi:10.1016/0002-9343(90)90282-I

56. Santiago JR, Nolledo MS, Kinzler W, Santiago TV. Sleep and sleep disorders in pregnancy. Ann Intern Med. 2001;134(5):396-408. doi:10.7326/0003-4819-134-5-200103060-00012

\section{Publish your work in this journal}

Nature and Science of Sleep is an international, peer-reviewed, open access journal covering all aspects of sleep science and sleep medicine, including the neurophysiology and functions of sleep, the genetics of sleep, sleep and society, biological rhythms, dreaming, sleep disorders and therapy, and strategies to optimize healthy sleep.
The manuscript management system is completely online and includes a very quick and fair peer-review system, which is all easy to use. Visit http://www.dovepress.com/testimonials.php to read real quotes from published authors. 